Intormational Bulletin No. 5

Montana Department of Agriculture Environmental Management Division Helena, Montana 59620-0205 1988

\section{DEC 21988}

MONTANA STATE LIBRARY 1515 E. 6th AVE. HELENA, MONTANA 59620

\title{
MANAGING GROUND SQUIRRELS WITH BAIT STATIONS
}

Bait stations have been used for many years to present rodenticides to commensal rats and mice. In recent years bait stations have been introduced as a method to control ground squirrels. Bait stations are devices containing a rodenticide bait from which ground squirrels feed. Bait stations are constructed to prevent animals larger than ground squirrels from entering. Other design characteristics include weather-tightness and sufficient bait capacity so that frequent refill is not required.

Anticoagulant baits are the recommended rodenticides for use in bait stations. Anticoagulants cause death primarily from internal bleeding and most require repeat feedings over several days to be effective. Anticoagulant products with the active ingredients Diphacinone or Chlorophanone are currently registered for use in bait stations to control ground squirrels in Montana.

Studies by the Montana Department of Agriculture showed bait stations were used by ground squirrels and that the anticoagulant baits tested were effective.

Department studies indicate bait station design seems to have little influence on their use by squirrels providing adequate access is allowed. From the applicators view there are several design characteristics that are important. In addition to providing adequate access for the squirrels a convenient access for replenishing the bait is needed. The station should be weather-tight to prevent bait spoilage. Moldy bait is poorly accepted, resulting in less effective control and disposing of unused, spoiled bait is costly. The station must hold a sufficient quantity of bait so the station need only be maintained once or twice a week. The stations need to be secured to the ground to prevent station upset and bait spillage by squirrels, livestock or other animals and wind. Figures $1-4$ illustrate some sample bait stations that have proven effective and are easily and inexpensively constructed by the user.
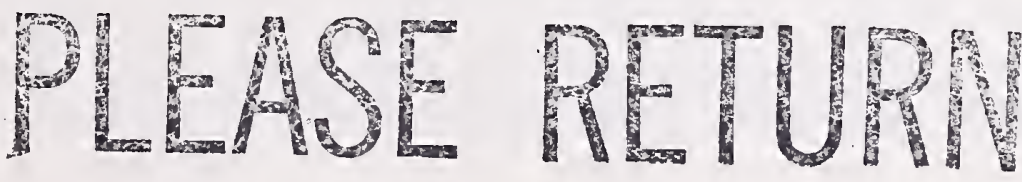
Bait station placement depends on squirrel density. Current information indicates maximum spacing be no more than 200 feet.

A minimum distance of 50-75 feet is sufficient even in densely populated colonies. Where the squirrel colony is isolated from other ground squirrels, stations should be maintained for at least thirty days. Where there is potential for reinvasion by new squirrels, stations may show continued use by squirrels for a longer period, perhaps for the entire summer season, as new squirrels continue to move onto the treatment area. Decrease in the rate of bait consumption is an indication that control is occurring. Typically, bait consumption is high initially and frequent station maintenance is required. As squirrel mortality occurs bait consumption gradually declines.

Set out bait stations in the spring when the squixrels first become active. A familiarization period where use of the stations slowly increases for a $1-2$ week period can be expected. Stations set out after young are born may result in young surviving the death of their mother. This can extend the length of time stations must be maintained.

Although prebaiting the stations with untreated grain is not necessary it is recommended. During the squirrels'

familiarization period toxic bait is not unnecessarily exposed to nontarget animals or inclement weather. After use of the stations by the squirrels has been well established the prebait is replaced by the toxic bait. The toxic bait will be fresh and since the squirrels have become accustomed to obtaining food from the stations it will likely be accepted faster and in greater quantity.

Applicators using anticoagulant baits must recognize they act slowly and patience is required. The applicator must also commit himself to regular maintenance of the bait stations to assure the squirrels have an adequate supply at all times. Stations that are frequently empty will result in poor control ard extends the period of time that stations must be operated.

Strychnine baits have been suggested for use in bait stations. Testimonial information has indicated some success with the use of strychnine baits in bait stations for control of the Richardson ground squirrel. Strychnine baits have traditionally given poor control of Columbian ground squirrels and its use in bait stations should not be expected to be any better than the traditional baiting methods with strychnine.

Strychnine is an acute, fast acting poison. Symptoms of strychnine poisoning occur within a few minutes after ingestion. Some ground squirrels exposed to strychnine bait may become sick before consuming a lethal dose and stop eating. Survivors exposed a second time to strychnine may associate their sickness with the bait and reject it, becoming bait shy. Because of this, hand or broadcast application of strychnine is not recommended more than once per year. Use of strychnine in bait stations 
repeatedly exposes surviving ground squirrels to the bait continually reinforcing the squirrels' aversion to the bait. For this reason strychnine is not recommended for use in bait stations.

Although use of bait stations usually reduces nontarget hazards, strychnine in bait stations may actually increase hazard to nontarget animals. If the contents of a bait station containing strychnine are spilled a large quantity of bait will be exposed greatly increasing the hazards to livestock and wildlife. Because death from strychnine poisoning is so rapid, numerous ground squirrel carcasses may be concentrated within a few feet of the station. The concentration of poison carcasses increases the hazard to predators and scavangers from secondary poisoning. Applicators intending to use strychnine in bait stations should assure the stations are sturdily constructed and well secured to the ground. All ground squirrel carcasses found should be routinely removed and deeply buried.

The addition of salt has been recommended by some to increase bait acceptance. Studies have shown lightly salted bait is no better accepted than unsalted bait. In fact, overly salted bait is likely to reduce bait consumption. Bait should not be scattered outside the station to induce use of them. The squirrels will use the stations as they become accustomed to them, even though it may take 1-2 weeks. Placing bait outside the station defeats its purpose by increasing hazard to nontarget animals and exposing the bait to weather.

Present evaluations indicate the most appropriate use of bait stations is on small acreages that contain isolated squirrel populations. Such areas might include ditch banks, small acreage crops and pastures, orchards and truck farms, cemeteries, golf courses and recreation areas.

Bait stations may also be used along crop borders to intercept squirrels moving from adjacent areas into the crop to feed or setup residence. Crop damage is unlikely to be eliminated by use of bait stations alone but damage might be reduced below a level of economic concern.

Use of bait stations on larger acreages might be considered in cases where use of grain bait has become ineffective or certain environmental hazards prevent the use of exposed baits. Although initially more expensive, bait stations using anticoagulant bait do work. Once ground squirrel populations have been reduced to a low level an annual maintenance program can be conducted at a much lower cost.

Bait stations do offer protection from primary poisoning to many nontarget wildlife species and domestic animals. They provide an alternative control method in areas where traditional control methods may be considered too hazardous to wildlife, domestic arimals and people. 
When using bait stations, particularly in areas open to public access, it is advisable for applicators to place warning sigris on the stations. Minimal information should identify the stations as containing poison bait, the active ingredient and where to obtain further information.

Consumption of ground squirrel carcasses can be hazardous to scavengers and predators. 'Their risk is reduced by the fact they must eat several carcasses over several days. Exposure to secondary nontarget animals can be reduced by montoring the treated area for carcasses and burying any that are found. Notify neighbors that treatment is occuring and advise confinement of pets to prevent them from straying on the treatment area. Any pet found displaying anticoagulant symptoms should be placed under veterinary care for Vitamin $K$ treatment.

Before using these or any other pesticide products carefully read and understand the pesticide label. When not in use store pesticides in locked storage. Always keep pesticides in the original, labeled container.

For additional information or assistance contact the Montana Department of Agriculture, Capitol Station, Helena, Montana 50620 .

$$
\begin{aligned}
& \text { In Helena Phone - (406) 444-2944 } \\
& \text { Daniel Sullivan }
\end{aligned}
$$

In Lewistown Phone - (406) 538-2182

Monty Sullins 
ligure 1. Ammunition box bait station. A. Oblique view. B. Side view.

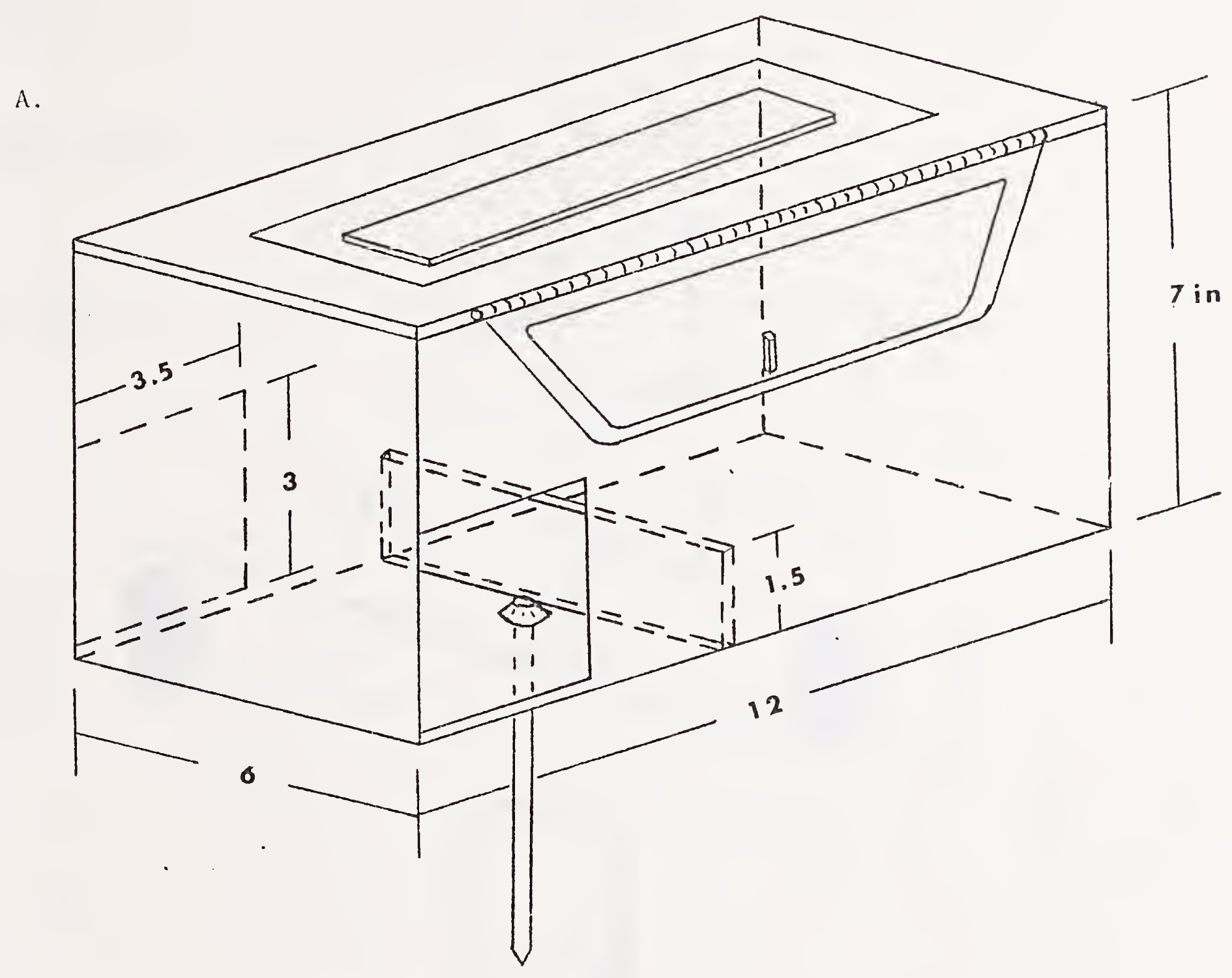

$B$.

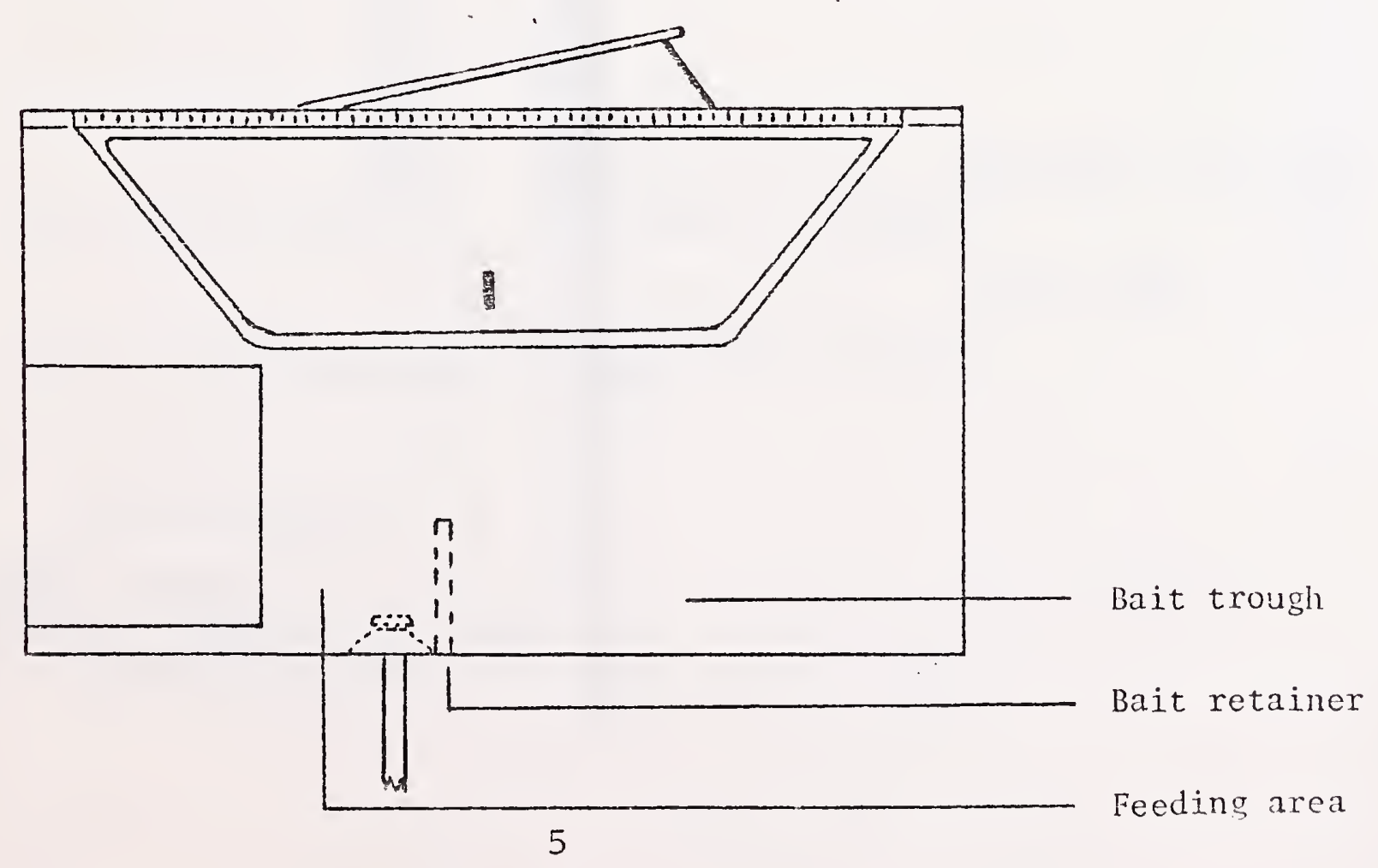


Figure 2. PVC pipe bait station. (Design by D. Sullivan, MDA)

A. External view B. Cross sectional view

A.

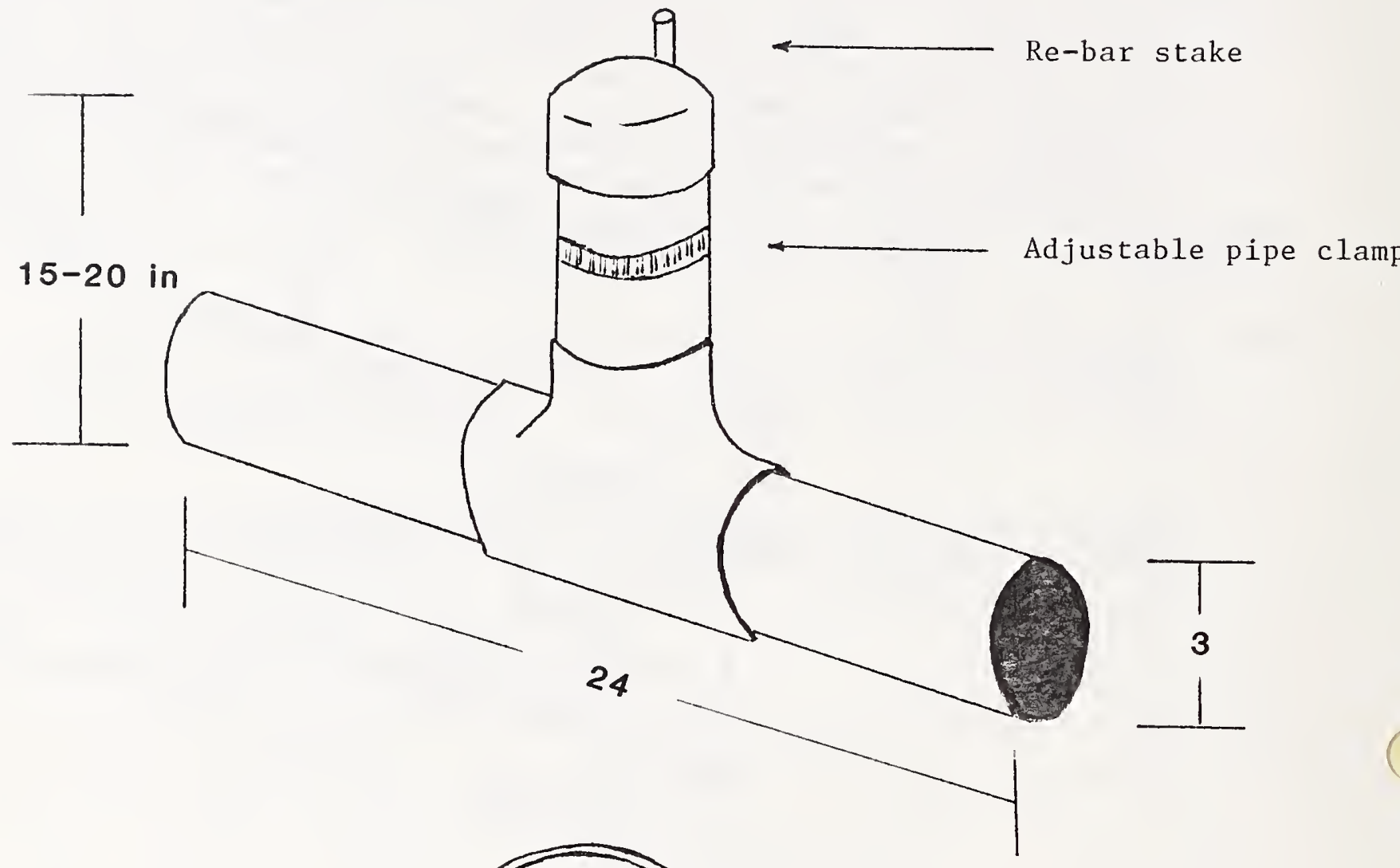

B.

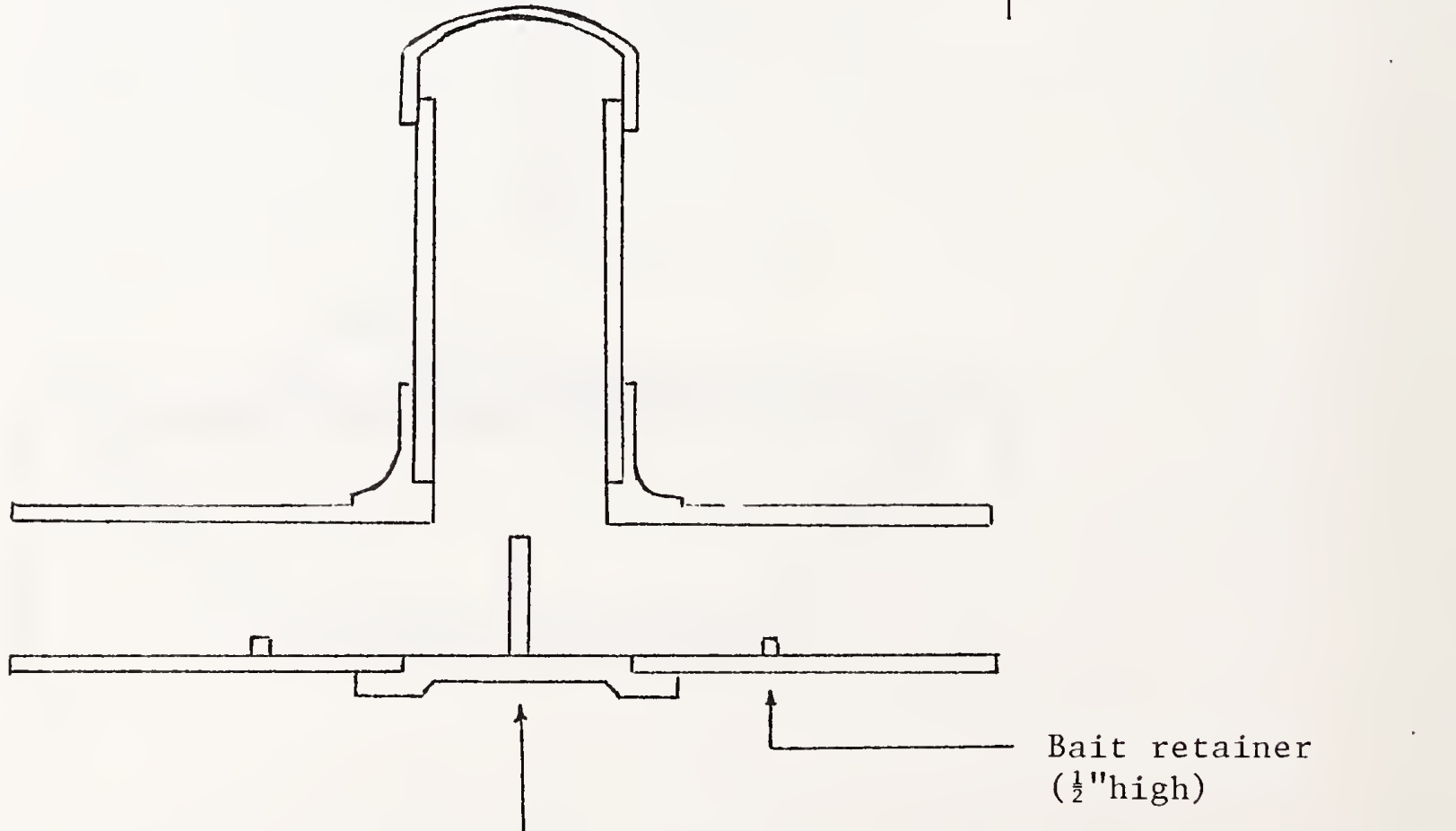

Divider- Prevents squirrels from passing through pipe and pushing bait out of the station. 
Figure 3. PVC pipe bait station (Design by S. Baril, MDA)

A. External view. B. Cross sectional view.

A.

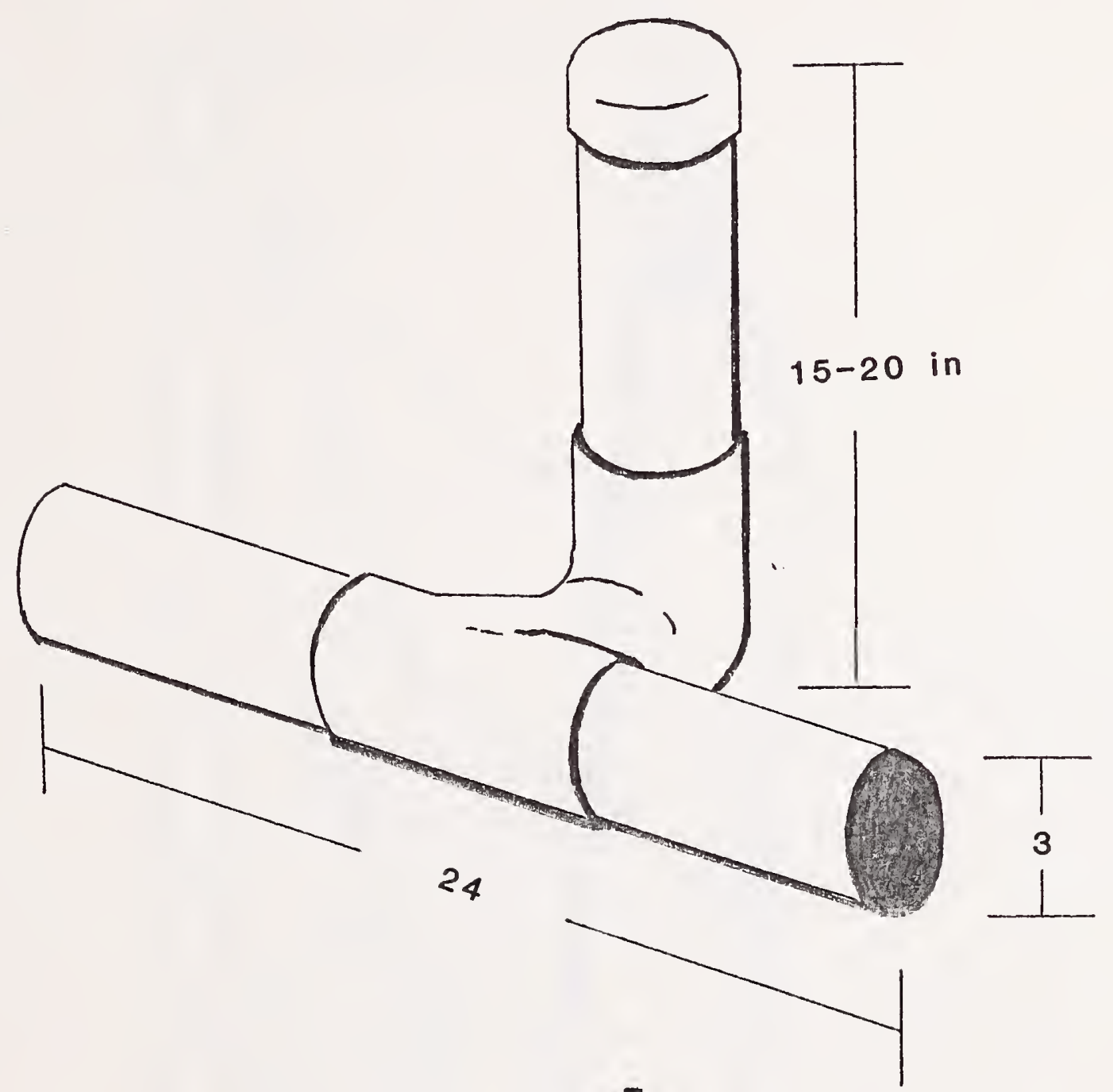

B.

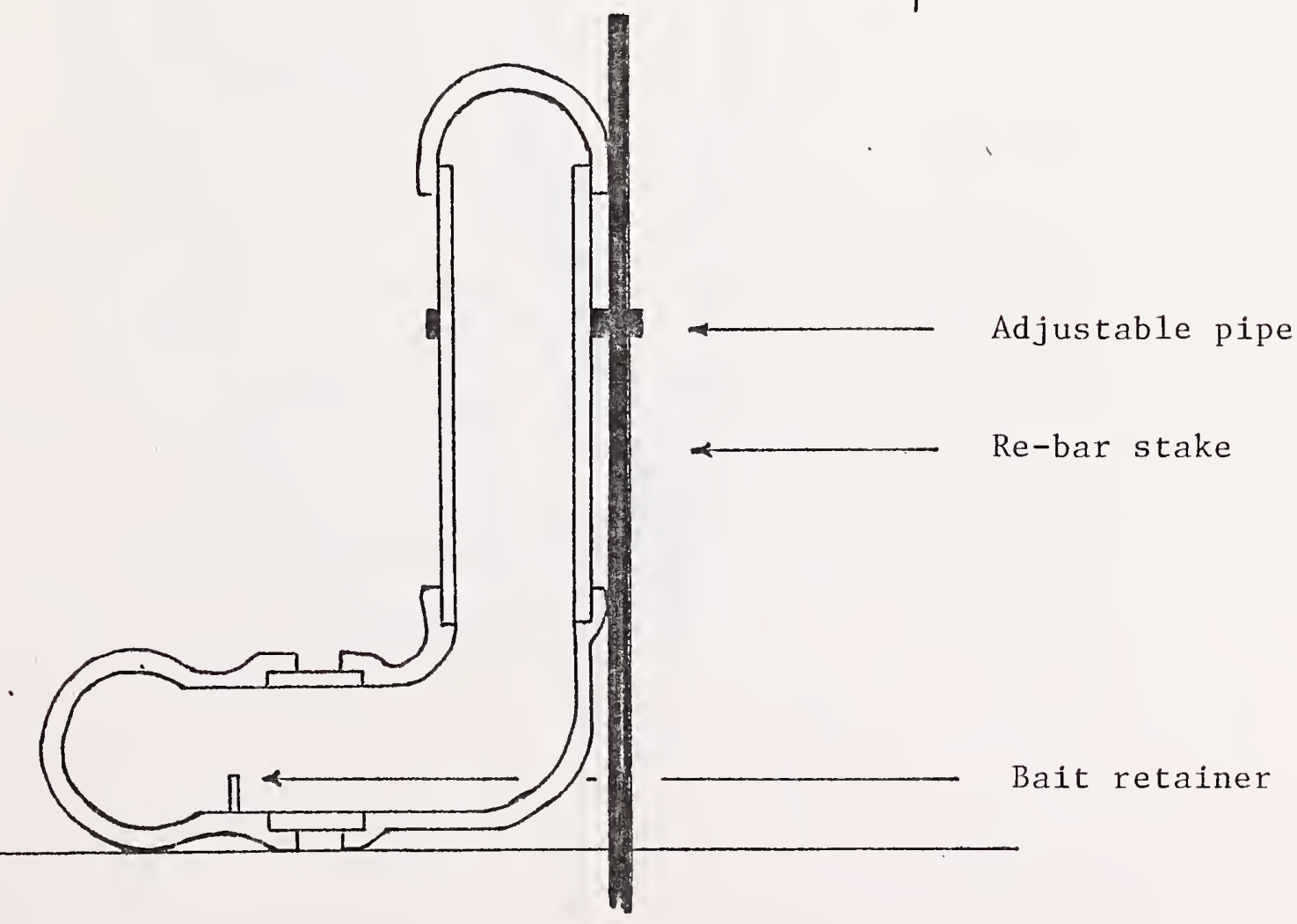




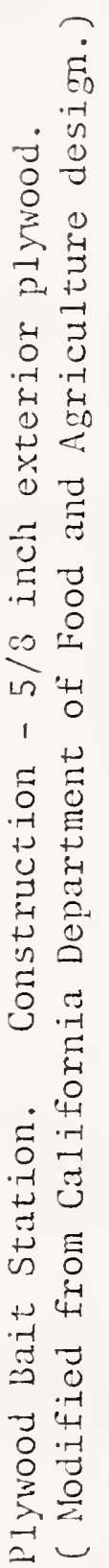

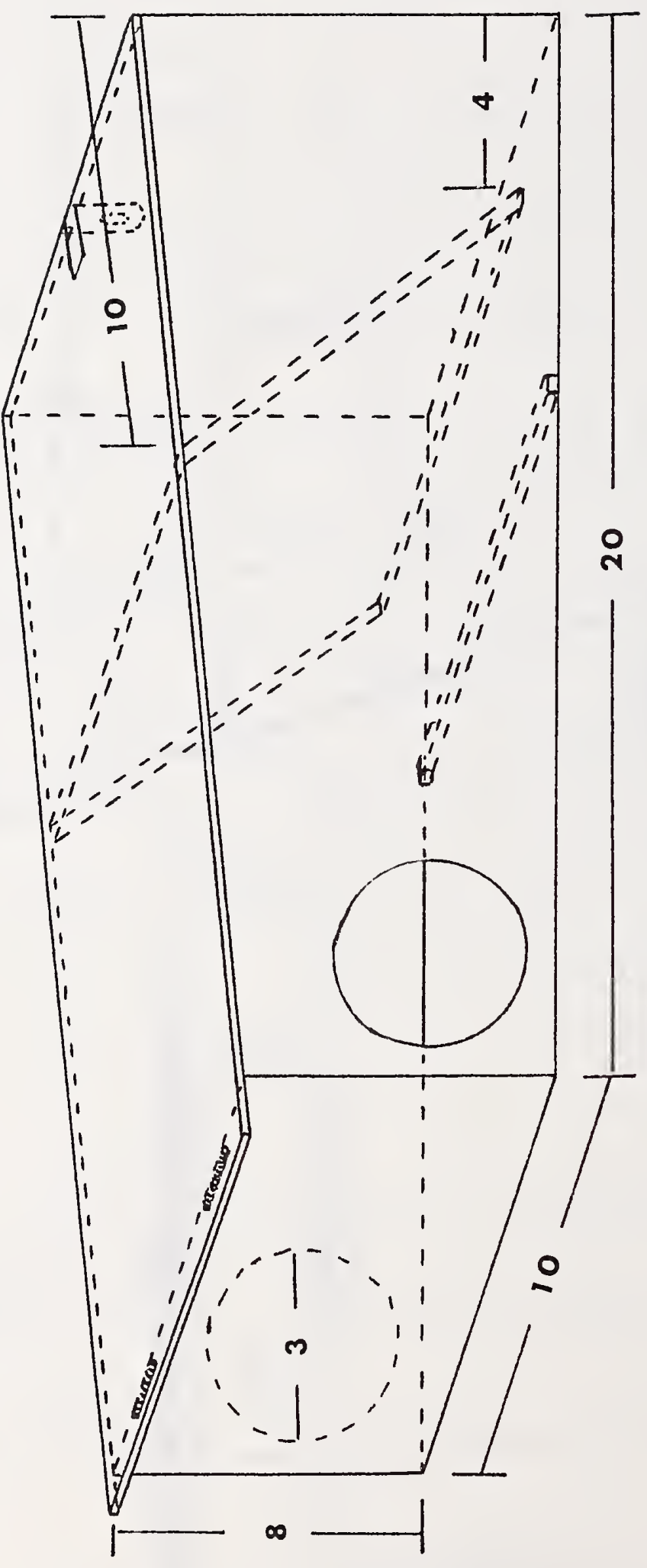

